\title{
The Effect of FIVES Strategy on Iraqi EFL University Students' Reading Comprehension and Writing Performance
}

\author{
*Hiba Hameed Ali, **Prof. Salam Hamid Abbas, Ph.D. \\ *M.A Student, English Department, University of Baghdad \\ College of Education for Human Sciences-Ibn Rushd-University of Baghdad \\ Baghdad, Iraq \\ **Professor ,English department, University of Baghdad \\ College of Education for Human Sciences-Ibn Rushd-University of Baghdad \\ Baghdad, Iraq
}

DOI: $10.37648 /$ ijrssh.v10i03.037

Received: 25 $5^{\text {th }}$ June, 2020; Accepted: 20th July, 2020; Published: $26^{\text {th }}$ August,2020

\begin{abstract}
Reading is an important skill that supports learning a foreign language. Comprehension is noticed to be the goal of reading .Reading comprehension refers to the ability to understand and comprehend written texts. Reading comprehension involves readers to identify the significant message of the text, and to relate readers' previous knowledge to the text. Thus ,proficient readers should draw their inferences about the author intention and to employ the various cognitive skills to deal with the text efficiently. Un fortunately, Iraqi university students still face difficulty in dealing a written text although they have studied English language for years.

The present study suggests to investigate the effectiveness of FIVES strategy on EFL university students' reading comprehension and writing performance, since it is said that FIVES strategy may offer great support for students to make learning meaningful and may connect reading with other skills such as writing to be developed at the same time.To examine the suggested study, a sample of (100) students from the second-year /Department of English/College of Education/University of Al-anbar, is chosen randomly during the academic year (2019-2020).This sample is divided into to groups the experimental group (50) students which is taught according to the FIVES strategy, and the control group( 48 students which is taught according to the conventional way..

Two instruments are utilized to show the improvement in students' performance reading comprehension and writing performance post-tests.According to the results obtained, the FIVES strategy is found to be effective in developing students' reading comprehension and writing performance.
\end{abstract}

Keywords: views of reading, concepts of comprehension, reading - writing connection, FIVES strategy, classroom Application of FIVES, RC by FIVES 


\section{INTRODUCTION}

Language acquisition entails the mastery of four abilities : reading, writing, speaking, and listening. Today, there is an orientation to teach language skills interactively. According to this orientation, reading and writing should be connected together in the teaching process ,as students' capability to incorporate what they read with their writing production, is considered fundamental in language development. This incorporation of writing with reading is likely to lead students to get the holistic view of language, and to be able to finish the assignment with the cooperation between the different language skills(Shanhan,2009:113).

As stated by Hirvela(2004), the reading and writing skills have in common the basic constructions consisting of the language structure ,competency attributes, and the features of the writing manner or mode. In this view, these skills are regarded as corresponding and complementary skills since, they share most of their roles .The interrelation of these skills involves three types of associations: rhetorical association which incorporates the same contact experiences contributed by readers and writers, procedural association which illustrates the practical effect of reading and writing on each other, and their essence aim well performance in educational and academic areas; shared knowledge and mental processes which covers the mental levels and steps followed in reading and writing and the knowledge of how the information are represented at different linguistic levels.(Fitzgerald \&Shanahan,2000:40).

Language acquisition demands the necessity for both the accessible and creative abilities that show an impact on our dominance of language. Reading is accepted to be the establishment in learning a language, it is an efficient way for cultivating students' information on language One of the major obstacles of the reading comprehension skill is the complexity in managing the intellectual and cognitive procedures that consist of a wide range of reasoning, investigating, interpreting, judging, predicting, and critical thinking Dominance of reading takes the integration of concepts to be obtained, information knowledge to be improved through which significance gist can be expanded and worked through the relation with a composed language (Harris and Graham,2007: 127). Harmer (2004 :86) expresses that deciding and determining essential information and thoughts in a written text, ignoring insignificant details, and initiating writing using learners own words are believed as necessary steps for an achievement in generating a good quality summary about the text itself.
This relation with the writing skill can illustrate the conception that the problems that face students in the reading skill can affect their writing performance since the major steps for working out a text can usually used in generating a draft of an article. Reading and writing are viewed as educational abilities that have corresponding systems. Al-Saadi (2019:3) states that Iraqi EFL students don't have elevated level in reading comprehension because of difficulty to process a written text efficiently, poor word identification, decoding capacities, and deficiency of language proficiency. Al-Udaini (2011:4) shows that most of Iraqi EFL students depend completely on bottom -up procedures when dealing with words investigation, abandoning the top-down procedures for the whole text.

Another source of the deficient dominance of a language is the generating of a text summarization which is found to be a not easy and cognitively demanding task . It is an important phase to be considered because of students poor performance ability to reconceptualize material.The important source of the problem faces Iraqi EFL students is the separation of the language skills in the teaching context. (Al-Rifa'i, $2013: 3$ ) .

This current study is intended to investigate the impact of using FIVES strategy(Facts, Inferences, Vocabulary, Experience, Summary) on Iraqi EFL university students' reading and writing performance .This study is an attempt to narrow down students' gaps in reading and writing, and to improve their capacity to summarize and get the significance from written language.

\section{AIMS}

The present study aims at finding out:

1. the effect of FIVES strategy on Iraqi EFL university students' reading comprehension.

2. the effect of FIVES strategy on Iraqi EFL university students' writing performance.

\section{HYPOTHESES}

It is hypothesized that:

1.there is no statistically significant difference between the mean score of the experimental group which is taught by FIVES strategy and that of the control group which is taught according to the conventional way in the reading comprehension post test.

2. there is no statistically significant difference between the mean score of the experimental group which is taught by FIVES strategy and that of the 
control group which is taught according to the conventional way in the writing performance post test.

\section{VALUE}

It is hoped that :

1. this study will be of great value to EFL university students to get benefit from the proposed strategy to improve their competency in reading comprehension and writing performance .

2.the study will be useful for EFL university teachers as an alternative strategy to be applied in their classrooms .

3.the study will be beneficial to curriculum designers to employ this strategy, to draw on the flexibility of materials and exercises intended for students' reading and writing skills improvement .

\section{VIEWS OF READING}

Nilson( 2003: 4) points out that the value of reading as a process which psychologically dealing with the language input relies on whether the reader get the composed text personally important which means if the text matches the reader's previous knowledge and life experiences, attention and personal needs. This concept is supported by Grabe and Stoller (2000) who state that reading is an interrelated action with specific function in which a significant association between readers and text is made. This interactive view of reading rejects the assumption that reading is a passive skill, within this view readers are considers to be active participants in the process of getting the meaning of a written passage .

Anderson (1985:48) argue that reading process involves readers in the way of building meaning from written content .This view is supported by Wixon(1987)who refers to the resources readers can make use of in the reading act which engages the readers' earlier background knowledge the text content and context in the construction of meaning, reading is the comprehending of a written text. He considers reading as consisting of two linked processes: word recognition and comprehension, defining word recognition as the procedure of receiving how written signs match ones of oral language whereas comprehension is the process of building the meaning of the text words and expressions .

This cognitive view matches Dechant's (1991:7) definition of reading who states that reading is a way of joining and combining the recognition and understanding of words, and with the lack of one of them, the reading process will be hindered. While Willis(2009:4) extends this view, illustrating that reading is the result of the matching of structures in the brain by the allocated systems and networks, these appear to be energetic to visual and aural reactions and to the extended memory.

However, Burns (1999) views reading as a difficult improvement that requires many advanced abilities such as concentration, recalling language and motivation .It is considered as a complicated activity that engages the basic contact between readers and the characteristics of the written language which associate with each other to process meaning, giving great attention to diverse factors as the language proficiency, previous familiarity with the text content and the attitude toward the subject of the text.

Thus, this cognitive perspective provokes the question "how such inner representations of the foreign language build up within the learner's mind?" This is also dealt with by Ausubel who refers to a significant difference between meaningful learning and rote learning. A pattern of rote learning is basically memorization of separated words or rules in a foreign language, thus ,the information turns to be temporary and easily to be lost. While, meaningful learning, other, happens when a new fact or rule is offered in an associated situation and is interrelated to the learner's earlier knowledge, in that case, it can be simply included into one's cognitive structure.

In the reading context, the process of reading engages the reader 's view about what one does while reading. This refers to the meta_ cognitive view of reading which deals with the tactics readers carry out during reading. According to this view of reading, the reader's job is not only to test the text, make inferences, verify or refuse them, but also to make use of several exercises in the reading process, which denote the stages of processing a text that can be divided into three, ones: before reading, while reading, and after reading.

1.Befor reading; the activities the readers engage before reading process are to recognize the purpose of the reading, classify the form or type of the text.

2.while reading; in this phase readers consider the general character and features of the form or type of the text, discover the author's purpose behind writing the passage, select, scan, or read to find details, generate predictions about what will happen next according to the information acquired previously, earlier knowledge, and evaluation taken within the preceding stages.

3. After reading; in this final stage, they try to outline a summary, bring a close, or inference of what was read.(Harris \&Graham,2007). 


\section{CONCEPTS OF COMPREHENSION}

Sargent, Smith, Hill, Morrison, and Burgess (2009) describe comprehension as "the understanding of text" and it frequently needs, "clarification, analysis, applications, viewpoints, ,and self monitoring" (p. 362). comprehension is the cause for reading. If readers can be able to read the words but can not know what they are reading, they are not actually in the process of reading. Competent readers are both decisive (they have a purpose to read) and active (they want to build a connection between what they read and their feelings).This gives a clear view of how the reading process relates strongly to comprehension, arguing that it is a way of initiating comprehension between the reader of the text and the writer. This view is supported by Snow(2002) who proposes that reading comprehension is the process that helps in getting the significant meaning of the written text, in this sense, attention is given to three elements: A) the reader who initiates the comprehension, taking into account all the skills, general ability, prior knowledge and personal experiences the reader conveys to the reading process. B)_ the text that is to be understood and processed by the reader. C) the activity in which comprehension is generated, including purpose, procedures, and significant results related to the reading process .

For the purpose of identifying how a reader gains knowledge from written language, scholars cannot ignore the importance of the four factors (increasing confidence, understandable texts, well_ matched content, and planned activities. It seems obvious from the previous view the importance of the comprehension procedures to gain the great attention for two reasons. First, the support it gives for in experienced readers in understanding written texts that include the information which expands their knowledge base. In this case, readers can deal with un understandable texts, that innovatively go against the traditional structure .Second ,another reason for focusing on procedures promoting comprehension is that they involve information expanding actions which are applicable in different context not only the reading context. From these factors readers can examine and operate their earlier knowledge and what is included in the text, assessing their understanding ability , checking possible expectations.

Accordingly, the idea that $\mathrm{RC}$ is a cognitive activity in which mental abilities are used by readers when they read a text , is supported by Burns and Ross (1984: 177) who consider that meaning is constructed from the composed texts within different comprehension levels. The level of comprehension denotes the fact that comprehension occurs within different deepness of understanding and different exploration of meaning.There are different levels of comprehension :The first, is literal comprehension which can be the more understandable and noticeable one. The process of comprehension at this level deals with the surface and exact implication of words. Within this level ,EFL teachers promote students to discover the facts and thoughts which are clearly included in texts. In this respect, it has been noted that in order to be able to read for literal meaning readers should have control over the contextual meaning of words.

The second level of comprehension is the inferential comprehension at which EFL learners can move to higher level in reading, looking for deeper meaning of words. They reach this level through critical way in reading, recognizing the associations among ideas, and the indirect meaning of these perceptions. This interpretive level involves mental procedures for example, reaching a conclusion and composing generality. While the third level of comprehension is critical comprehension in which thoughts and facts can be evaluated .Critical judgment and decision can be raised simply when learners have the ability to realize and appreciate what they read in the text, and when they emotionally respond to the author's title, character or language style.

\section{READING AND WRITING CONNECTION}

Reading comprehension and writing in an unfamiliar language context is viewed as the most old established and practical abilities equally be trained or educated in the learning context. In addition, the skills of reading and writing have been considered to be learned together not in isolation for each and every level that can be connected strongly in language learning that it is similarly agreed with the claim " high-quality writers can be excellent readers, excellent reading and the ability to analyze a text well can give an efficient means to be a proficient writer... In the daily practice of language, the skills of language have been frequently integrated or exchanged with other skill. This efficient combination can be highly seen in the foreign or second language context

Different models and processes identify reading and writing associations. According to the conventional method, the skills of reading and writing are regarded as separate abilities and exercises that have to be evaluated and educated as distinct skills and tactics. Nowadays, both skills are argued to be taught together and expressed as equivalent practices or "natural partners" in which the actions that readers use are matching or fitting with the tricks which the authors follow The logical reason of regarding reading and writing to be "parallel" since there will be great relations what readers carry out and what 
reporters or writers make when they practice reading or writing: as they can show the ability to construct gist through a passage (through writing process), and as they can reflect on the text (through reading). On the other hand, the accurate type of these associations is attentive, but it does not show correctly any specification. Investigators from a mixture of domains (e.g. teaching, writing instructions, reading, and learning mentality) have shown great interest in the habits and procedures where the skills of reading and writing may strengthen and support the knowledge of subject matter, the improvement of proficiency aptitudes, and the achievement of language capability (Grabe, 2003:242).

The reading and writing connection is regarded as subject of interest in the educational institutions because of its strong relation with learners whether they are dealing with first language (L1) or a second language (L2).The interest in connecting writing and reading together involves the requirement to construct this association on assumptions and frames in order to illustrate how writing and reading collectively can improve language level, proficiency, and content knowledge. These outlines and frames present educators and instructors a prosperous perception of how to formulate a course intended to encourage proficiency and language ability required for successful performance in academic context

As a matter of fact, it is regarded as an elderly recognized method that students can involve through the reading comprehension lessons to understand or generate short sentences from the original text, whether it can occur within or after reading and understanding the written passage. The capacity to create a brief passage from the original text is described as summarization in TEFL literature which involves learners to use certain skills and tools to generate a precise summary, and is regarded to be one of the essential component when reading comprehension is taught and tested. At educational situation in specific, several summarization tasks have to be generated, undergraduates frequently require to construct and finish a variety of précis summary tasks that call designed for the integration of a written fabrics in different production

\section{FIVES STRATEGY}

The components of fives refer to a proficiency or aptitude for getting idea, the significance point, and key words in a passage .These components stand for private associations with the previous information, facts and the special experiences, involving and developing a private implication and interpretation, conveying it precisely and successfully.(Shea ,2011:8).

F represents facts. Before peruses have the skill to shift to more elevated levels of speculation on blossom's taxonomy, they have to procure realities to work for taking part in more profound degrees of constructing meaning. The reality level(fact) is communicated as an action word recollecting(remembering) instead of as a thing information(knowledge). It is fundamental that readers review the expressed realities precisely and recognize key thought from remarkable details and stimulating.Handling facts includes two intellectual functions: readers will be required to adapt thoughts and afterward suit them in their diagram (foundation knowledge)for that subject. Adaption includes the getting of facts, terms implications, practical terms in a passage, and the acquiring event of realities as the fundamental elements for advanced _ rank with new and earlier facts. Accommodating happens when the reader has thought about whether the fact is reliable with what he knows or can be adjusted in a manner to fit in with what he knows(Gunning ,2010)Accommodated fact is productively associated with other related sources of knowledge about the subject of the text. Accommodation includes investigation and assessment of fact, analyzing it's exactness and consistency with earlier information and experiences that works at all degrees of reasoning.

I stands for making inferences. Readers set out to find the real story, including what's in the content substance to what's in their brain (foundation information) and experiences to develop an inference(Shea,2011:12).It is essential to recollect and regard that life's conditions and chances, and culture have formed the previous knowledge and real life practices that readers can pass to a passage. In spite of the fact that deductions are worked from this blend, content _ based inferences are those bolstered with a dominance of information unambiguously expressed in the written passage ; information _ based inductions are profoundly upheld by readers' experiences as these associate with content in the text. As readers build derivations, they customize comprehension of text substance .

V represents for vocabulary knowledge. writers utilize exact words to explain their significance point , diminishing the potential for misconception.A number of words might be new or ambiguous in the setting in which they may be discovered .It is the duty of readers to completely get words, and articulations as utilized with regards to the setting of the written text they comprehend . Understudies who have constrained vocabularies suffer to comprehend grade_ rank text passage, predominantly instructive determinations. This is valid for English 
Language students, who are inviting for exploring substance and guidance identified with it .Informational (interpretive) content is particularly loaded with phrasing that is a point specific. In any content sort, readers may run over numerous words that they have not recently met in print or heard discussions (Shea,2011:194).

E represent experiences and life practices . Readers expound, extend, assess, and make associations depend on life expertise (from previous information and life ).Every day, we unknowingly construct associations with stimuli that affect our faculties; it's instinctual to translate approaching data and interface new information to what we recognize or have encountered .Readers ought to do this when drawn in with the text content ; basically interpreting words is in adequate .Reading includes dynamic speculation all through the way toward connecting with the content. So as to absorb and suit it ,readers think about how innovative data interfaces with their earlier information and encounters .Directing them to think diagnostically, share thoughts obviously, and utilize their decisions for a more profound comprehension of the content substance is a basic piece of successful proficiency guidance.

$\mathbf{S}$ is for summary writing which the reader rewords the substance of the content with a small portion of inference_or nothing at all .Readers uncover the precision degree and profundity of their understanding, capacity to recognize central thoughts and noteworthy refinement, and level of clearness in communicating what they have gathered from the text. Effective outlines include significantly more than simply stimulating subtleties from the written passage. Summaries pick significant thoughts , put aside un significant and excess . subtleties, rethink data , report thoughts in a proper arrangement ,and build a point judgment when the writer doesn't give or expressly state one .All of this is cultivated in a brief organizations enabling readers to personalize key thoughts such that makes recalling simpler and landing them for use in advanced stage reasoning practices. It is a full of meaning, multifaceted procedure that involves clear instruction, efficient demonstrating, and valid practice.

The process of summarizing turns into a continuous meta intellectual conduct when readers self_screen perception, framing brief mental outlines as they explore through complex text. This essentially builds maintenance and develops general understanding of that content .Readers are actuated to take part in abbreviating just as every one of different abilities and submit them deliberately and adequately by the inquiries they present for themselves.(Irwin,2007:25).

\section{CLASSROOM APPLICATION OF FIVES}

\section{A. FIVES With Pre Reading}

Before the reading process, the teacher presents the content, representing the text in a way that involves how to review it by reading quickly using labels , headings , subordinate headings and different hotspots for pieces of information relating to its specific situation. Then, the teacher calls students for generating anticipations , recommending what they anticipate that the content should be about the information it will contain. In this phase, the teacher encourages students evaluating expectations, in the event, they are coherent dependent on the content they have right now.

\section{B.FIVES Within Reading}

Anticipations can be adjusted at the time of reading and primary associations are inspected. Rehashing is a profoundly productive and powerful repair _ up technique . In classes, halting at suitable spots to talk about substance turns out to be productive. It enables students to be locked in with others' thoughts and mind. Such fractures develop into checkpoints for retaining information, considering it, and getting ready plans to go on .This causes students to outline one's reasoning _ concepts_ responses , and associations during reading that aides comprehension .This step can be upheld by framing questions.

\section{C.FIVES Within Post Reading}

This phase of the chain enables students to review, combine, sort out, and summarize. Students through this stage can utilize other language procedures, for example, paying attention to others, discussing thoughts, building notes before reflecting individual understanding and experiences .Post reading organized associations identified with the content, extend cognition just as reinforcing students' language aptitudes : they construct certainty and community. The instructor guides note taking depending on understandings created during debate. After a complete and wealthy discourse, the instructor guides the perspective (S) of FIVES that is the focal point of exercise before controlling students' training.

\section{RC BY FIVES}

The primary concern in any association with content is understanding. Without comprehension, a passage will not be processed; it would be just words expressed or saw. Any methodology for comprehension and learning won't be viable if just practices in disengagement with model content and reaction sheets. The center turns out to be doing the means instead of utilizing the technique in an individual, self_started, and vital way, one intelligently coordinated to 
text. The presenting, rehearsing, and incorporating each progression of FIVES would resemble an adventure that coordinated by the way toward translating a ambiguity message through an investigation of its phonetic examples to reach at a comprehension of the message that is the essential goal of the action.(Swanson \&Law as cited in Shea, 2011:40).

Irwin (1991) demonstrates understanding as a difficult intellectual act including the consistent incorporation of micro and macro practices. This form is not worked in a random path; readers can shift repeatedly as they utilize the micro and macro processes, using intellectual functions in exclusive manners for written passage. Just

FIVES is presented step by step, demonstrated, and bolstered in guided practice and free practice, at the same time, as they are found out, each is incorporated with the following one. The attention is on constructing proficiency with the elements so as to relate them comprehensively to the errand(Shea 2011:26). At the point when understudies have absorbed every one of the means of FIVES to the purpose of personalizing and self-utilizing their interrelated employ, it turns out to be less about the procedure practice and increasingly about vital usage with every content would be met, bringing about full comprehension of the writer's message and compelling individual reacting.(Irwin,2007)

\section{Micro practice}

In the first place, there is the smaller scale process that incorporates comprehending words utilized in a passage alongside piecing words (hanging together) into significant expressions and sentences. So as to adequately perform that, readers have to comprehend the importance implications expressed by the words in the setting they are utilized. This aptitude is a basic part of familiarity. The $\mathrm{V}$ in FIVES assists students with seeing significant, fascinating, and complex words in a written text and recognize that they have to consider, examine as well as explain these so as to completely comprehend - get the essence of - the author's message.

The Subsequent step will be the associating procedure; this may require crossing over sentences and sections together, realizing word reference utilized crosswise over sentences, and making smaller than expected derivations among sentences and sections.

\section{Macro Practice}

The macro processes can direct the receiving of the text essence, the huge thought or the general significance. This is confirmed by students' capacity to compose thoughts and convey right picture that reflects full comprehension of what they've paid particular attention to.
- a summarizing $(\mathrm{S})$ is dissimilar from retelling. "In a summarizing the objective is to be brief as opposed to incorporate individual understandings and determinations as in a retelling

\section{Elaboration}

The following phase is the elaborative stage in which students can develop the significance point of the text . They can generate assumptions, coordinate related previous information and experience, make space for full of feeling reactions, and take part in more advanced level of reasoning. Now, the reader constructs associations with the content $(F)$, previously founded information from different sources $(\mathrm{F}+\mathrm{E})$, and individual experiences on the globe (I $+\mathrm{E})$. The focus is consistently on giving proof or a justification to individual implications that have been developed

\section{Meta cognitive practice}

Finally, it will be the meta cognitive perspective in which readers or readers observe their claim understanding and apply fix-up methodologies. They can return to replicate or they request repeation of explicit facts that was ambiguous; they offer conversation for explanation. Meta cognition associates with "students' earlier information and utilization of their own intellectual sources " and this may assist in clarifying implementation levels, and suggest a hypothetical structure for arranging instructional negotiations to advance more prominent methodology use among readers.

As readers do such, they expound in manners that reflect higher _ level reasoning, powerful reactions, and predictions .They construct associations, and fix perplexities, and pose investigations in the absence of comprehension. The expanding of "why" is the readers' device to judge and evaluate what the person has read .This includes attentively reflection by the reader and combination that follows whole _part _ whole rhythm to learning (Garner,1987:44).

\section{METHODOLOGY}

This section deals with the method followed in order to get the data analysis and data results which are based on three points: (i) a sample of the study,(ii) the instrument involved consisting of pretest and posttests, and (iii) The statistical methods implemented for statistic information analysis.

\subsection{Population \&Sample}

In the current study, the population represents all Iraqi EFL 2nd year University students at the Colleges of Education, English department ,except Kurdistan Region. 
College of Education/University of Al Anbar is selected randomly from which the sample has been elicited .

The total number of the 2nd year students is (120students)male and female represented in two sections ;

A and B. The total number of the sample is ( 98 students) after the excluding of the repeaters and primary teachers. Section A is randomly selected to be the experimental group which consists of (50 students) where as section B is randomly selected to be the control group which consists of (48 students).

\subsection{Equalization}

For the sake of not to cause any variance in the performance of the involved participants, it is very significant to ensure the equalization of the two groups involved in this experimental work .This checking is achieved by considering the following variables: Level of Intelligence, Level of Academic Motivation, Students' Attitude Toward Reading, Students' Attitude Toward Writing, Gender, Reading Comprehension Pre-test, Writing Performance Pre-test.

\subsection{Instruments of the Study}

In this present study two instruments are used to achieve the aims of this experimental work. These are a reading comprehension posttest and a writing performance posttest which are both constructed by the researcher.

\section{The Reading Comprehension Post Test}

1. A reading comprehension post test is constructed to accomplish the first aim of this study. This test is composed of four questions in which each question consists of an un seen passage selected by the researcher from different internet sources to be suitable to students' level and interest. The RC post test consists of the following four questions: The first question consists of an unseen passage about video games and why they can be good for people. This text is followed by a multiple choice question which is scored out of 10 .

2. The second question consists of an unseen passage about bees and nature and the role they play in nature. This text is followed by a True/False question which is scored out of 10 .

3. The third question consists of an unseen passage about summer Jobs or work experience for students and it's advantage for students to develop their career future. This text is followed by a completion question and students are required to complete the gaps from the text .This question is scored out of 10 .

4.The fourth question consists of an unseen passage bout cinema and technology. This text is followed by a cloze test that involves students to complete the text with suitable words from their own ones .This question is scored out of 10.

\section{The writing performance Post - Test}

To achieve the second aim of this study, a writing performance post-test is used . The topics of writing performance test is chosen according to the students' interest and attitude in order to be sure that most students in both groups are provoked to take the test enthusiastically and even those with low level have something to write about . This is accomplished by introducing students to an open questionnaire .

According to the open questionnaire introduced to the students in both groups, five topics are introduced to the jurors who are experts in the field of ELT to select the most suitable topic for the second year university students. The analytical scoring scheme that is proposed by Brown(2007) is utilized for scoring the writing performance test.

\section{Final Administration of the Instruments}

After the ensuring of the validity and reliability of the two tests, the RC and WP test are administrated on both groups of the study after the end of the experiment. This final administration is applied on 23 January ,2020.

\section{DATA ANALYSIS, DISCUSSIONS OF RESULTS, CONCLUSIONS AND RECOMMENDATIONS}

\section{Results Related to the First Hypothesis}

In order to examine the first hypothesis which reads that " there is no statistically significance difference between the mean score of the experimental group which is taught reading according to the FIVES strategy and that of the control group which is taught according to the traditional way in the RC Post_test".

After the administration of the RC post _ test on both groups . The data achieved is statistically manipulated. The $\mathrm{t}$ _ test formula for two independent samples is used to find the statistical differences between the two groups. See table I 
The Mean Scores, Standard Deviation and T-Test Value for Both Groups in the RC Post-test

\begin{tabular}{|c|c|c|c|c|c|c|c|}
\hline \multirow[t]{2}{*}{ Groups } & \multirow{2}{*}{$\begin{array}{ll}\text { No. } & \text { of } \\
\text { Students } & \end{array}$} & \multirow{2}{*}{$\begin{array}{l}- \\
X\end{array}$} & \multirow[b]{2}{*}{ S.D } & \multicolumn{2}{|l|}{$T_{-}$Value } & \multirow{2}{*}{$\begin{array}{l}\text { Degree of } \\
\text { freedom }\end{array}$} & \multirow{2}{*}{$\begin{array}{l}\text { Level } \\
\text { of } \\
\text { significan } \\
\text { ce }\end{array}$} \\
\hline & & & & $\begin{array}{l}\text { Computed } \quad t \\
\text { value }\end{array}$ & $\begin{array}{ll}\text { Critical } & \mathrm{t} \\
\text { value } & \end{array}$ & & \\
\hline EG & 50 & $\begin{array}{l}30.58 \\
0\end{array}$ & 4.678 & 6.015 & 2.000 & 96 & 0.05 \\
\hline CG & 48 & $\begin{array}{l}24.70 \\
8\end{array}$ & 4.985 & & & & \\
\hline
\end{tabular}

it is found that the mean score of the experimental group is (30.580) and that of the control group is (24.708) . The computed $t$ for the experimental group is found $(6,015)$ which is higher than the critical value which is $(2.000)$ at degree of freedom (96) and level of significance (0.05). This means that there is a statistically significance difference between the mean score of the two groups in the RC post _ test. So, the null hypothesis is rejected.

\section{Results Related to the Second Hypothesis}

In order to verify the second hypothesis which reads that "there is no statistically significant difference between the mean score of the experimental group which is taught reading according to the FIVES strategy and that of the control group which is taught according to the conventional way in the writing performance post test".

To check the verification of this hypothesis, a writing performance post - test is administered for both groups. The data achieved is statistically manipulated by using T - test formula for two independent samples. See table 4.2

Table II

The Mean Scores, Standard Deviation and T-Test Value for Both Groups in the WP Post-test

\begin{tabular}{|c|c|c|c|c|c|c|c|}
\hline \multirow[t]{2}{*}{ Groups } & \multirow{2}{*}{$\begin{array}{ll}\text { No. } & \text { of } \\
\text { Students } & \end{array}$} & \multirow{2}{*}{$\bar{X}$} & \multirow[t]{2}{*}{ S.D } & \multicolumn{2}{|l|}{$T_{-}$Value } & \multirow{2}{*}{$\begin{array}{l}\text { Degree of } \\
\text { freedom }\end{array}$} & \multirow{2}{*}{$\begin{array}{l}\text { Level } \\
\text { of } \\
\text { significance }\end{array}$} \\
\hline & & & & $\begin{array}{ll}\text { Computed } & t \\
\text { value }\end{array}$ & \begin{tabular}{ll|} 
Critical & $\mathbf{t}$ \\
value & \\
\end{tabular} & & \\
\hline EG & 50 & 12.940 & 1.984 & \multirow[t]{2}{*}{5.814} & \multirow[t]{2}{*}{2.000} & \multirow[t]{2}{*}{96} & \multirow[t]{2}{*}{0.05} \\
\hline CG & 48 & 10.667 & 1.883 & & & & \\
\hline
\end{tabular}

As shown in table II the mean score of the experimental group is found to be (12.940), and the mean score of the control group is found to be (10.667). The computed t value (5.814) is higher than the critical value which is (2.000). This means that there is statistically significant differences between the two groups in the WP post_ test . So the null hypothesis is rejected.

\section{The Size of Effect Using ETA - Square}

To find out the size effect of effect of the examined strategy on students' RC and Wp, ETA_ Square formula is used .

\section{The Effect Size on Students' RC}

To find out the effect size of the FIVES strategy on students' RC, ETA_ Square formula is used . See Table III 
Table III

The Mean Scores, Standard Deviation and Computed T Value for Both Groups in the RC Post-test

\begin{tabular}{|l|l|l|l|l|l|}
\hline Groups & - & S.D & $\begin{array}{l}\text { Degree } \\
\text { Freedom }\end{array}$ & Computed t value & Size Effect \\
\hline EG & $X$ & 4.678 & 96 & 6.015 & 0.27 \\
\hline CG & 24.708 & 4.985 & & & \\
\hline
\end{tabular}

As shown in this table, the value of the effect is found to be $(0.27)$. So this indicates that this strategy has a great effect on Iraqi students' RC .

\section{The Size of Effect on Students' WP}

Utilizing the ETA_ square formula shows that the value of effect is found to be $(0.26)$. This indicates that this strategy has also a great effect on Iraqi students' WP. See Table XI

Table XI

The Mean Scores, Standard Deviation and Computed T Value for Both Groups in the WP Post-test

\begin{tabular}{|l|l|l|l|l|l|}
\hline Groups & $\bar{X}$ & S.D & $\begin{array}{l}\text { Degree } \\
\text { Freedom }\end{array}$ & Computed t value & Size Effect \\
\hline EG & 12.940 & 1.984 & 96 & 5.814 & 0.26 \\
\hline CG & $\mathbf{1 0 . 6 6 7}$ & $\mathbf{1 . 8 8 3}$ & & & \\
\hline
\end{tabular}

\section{CONCLUSIONS AND RECOMMENDATIONS}

According to the results and the findings of the experimental work, it is concluded that:

1. Putting in an application the teaching strategy of FIVES is realized to have a positive impact on developing Iraqi EFL students' ability in reading comprehension.

2. Through the use of FIVES strategy it is found to have great positive effect on improving Iraqi EFL university students' writing performance .

3. Applying the FIVES strategy increases the chances of students to integrate the language skills to build students' proficiency in language.

4. Following the FIVES strategy breaks the routine of 3. our classrooms in following the traditional way of teaching ,this strategy puts student to be the focus in the lesson and reduces teacher's intervention.

5. FIVES strategy is proved to develop students' ability in summarizing texts, which in turns develop their writing ability to express their opinion and reflect how the text touches their prior knowledge and experiences to be away from memorizing every single word.

6. $\quad$ FIVES strategy makes joining between micro and macro skills that moving students to get the higher5.EFL instructors should take into considerations students' cognitive level to create and evaluate their own work and others work.
In the light of the results obtained and conclusions ,the following recommendations are put forward :

1. EFL educational program creators and leaders in the Ministry of Education are called to take into consideration and incorporate various RC and WP tasks that can be taught by efficient education strategies like FIVES, since they have a great impact in developing students' understanding and conception in all phases of learning.

2. EFL instructors ought to know about the significance of advancing students' capacity of grasping the written text meaning and message, and its impact on students' fulfillment in other language scopes.

EFL educators should give a valiant effort to make safe, agreeable, and relaxing condition in their teaching setting to encourage their students develop their RC and WP capacity.

4. This strategy lessens the educator's responsibility of teaching as it allows EFL students the chance to have a possibility to take part initiating and enhancing the learning path and procedure. Consequently, EFL instructors ought to be aware enough in realizing when to permit students take the responsibility for their own work, and when to intervene or with giving them help.

attitudes individual differences and levels. They should follow these consideration in choosing the topics and the teaching strategy in order to lead students toward higher level of performance in language skills. 


\section{REFERENCES}

Al-Rifa'I, F.K. (2013) Measuring EFL Students' Reading Comprehension Efficiency in Related to Text Type. Unpublished M.A. Thesis College of Education / IbnRushd. University of Baghdad.

AL-Saadi, Z , M, H .(2019)"The Effect of SQ3R Strategy on Iraqi EFL Preparatory School Students' Reading Comperhension". M. A Thesis.Iraq

Al-Udaini, Alaa Ali (2011) The Effect of Computerized Program on Developing 9th Grades' Reading Comprehension Skills and Attitudes towards Reading in Palestine. M.A. thesis. College of Education. The Islamic University Gaza.

Anderson, et al .(1985) Becoming a Nation of Readers: the Report Commission on Reading. Washington, D.C: National Institute of Education.

Burns, A., and Ross, P. (1984) Teaching in Todayes Elementary School (3rded.). New York: Longman

Dechant ,E.1991.understanding and teaching reading. Hillsdale ,nj: Lawrence Eribaum Associate

Fitzgerald, J., \& Shanahan, T. (2000). Reading and writing relations and their development. Educational Psychologist, 35(1), 39-50.

Garner, R. (1987). Metacognition and reading comprehension. Norwood, NJ: Ablex Publishing.

Grabe, W.(2003). Reading and writing relations: Second language perspectives on research and practice. In Kroll, B.

Harris, R.and Graham ,S.(2007)Teaching Reading Comprehension to Students with Learning Difficulties .New York :The Guilford Press.

Irwin, J. (1991). Teaching reading comprehension processes (2nd ed.). Englewood Cliffs, NJ: Prentice Hall.

Irwin, J. (2007). Teaching reading comprehension processes (3rd ed.). New York, NY: Pearson, Allyn \& Bacon.

Nilson, J. M. (2003). The impact of explicit self-regulatory reading comprehension strategy instruction on the reading specific self-efficacy attributions and affect of students with reading disabilities. Learning Disability Quarterly, 29, 213230. doi: $10.2307 / 30035507$

Shanahan, T.(2009)Connecting Reading and Writing Instruction for Struggling Learners .In G.A .Troia(ED).Instruction and assessment for struggling writers: Evidence -based practices .New: York :The Guilford Press).

Shea, M.(2011). Parallel learning of reading and writing in early childhood. New York, NY: Routledge, Taylor \& Francis. 